Turk J Cardiovasc Nurs 2020;11(26):155-158

\title{
Hemşire Yönetimindeki Kardiyak Rehabilitasyon Kliniği: Malta Mater Dei Hastanesi Deneyimi
}

\author{
(D) Sibel Sevinç \\ Hatay Mustafa Kemal Üniversitesi, Sağlık Bilimleri Fakültesi, Hemşirelik Bölümü, İç Hastalıkları Hemşireliği Anabilim Dalı, Hatay
}

\begin{abstract}
Özet
Kalp ve damar hastalıkları Ülkemizde ve dünyada mortalite ve morbidite açısından en önde gelmektedir. Kalp hastalıkları sonrasındaki kardiyak rehabilitasyon düşük maliyetli bir girişim olarak kabul edilmektedir. Bu girişim ömrü uzatır, tekrarlayan hastane yatışlarını ve sağlık harcamalarını azaltarak prognozu iyileştirir. Kanıtlar, hemşire olgu yönetimi ve hemşire-eşgüdümlü multidispliner korunma programlarının kardiyovasküler riski azaltmada olağan bakımdan daha etkili olduğunu ve çeşitli sağlık kuruluşlarının koşullarına uyarlanabileceğini göstermektedir. Bu makalede hemşire yönetimindeki kardiyak rehabilitasyon kliniği, Malta Mater Dei hastanesi örneği paylaşılmıştır.
\end{abstract}

Anahtar sözcükler: Hemşire; kardiyak rehabilitasyon; malta mater dei hastanesi.

\section{Nurse-Led Cardiac Rehabilitation Clinic: Experience in Malta Mater Dei Hospital}

\begin{abstract}
Cardiovascular diseases are the leading factors in terms of mortality and morbidity in our country and in the world. Cardiac rehabilitation after an acute coronary event is considered a low-cost intervention; it improves prognosis by prolonging life while reducing recurrent hospitalizations and health expenditures. Evidence indicated that nurse case management and nurse-coordinated multidisciplinary prevention programs are more effective than usual in reducing cardiovascular risk and can be adapted to the circumstances of various health care facilities. In this article, a sample of Mater Dei hospital Nurse-Led Cardiac Rehabilitation Clinic in Malta is presented.
\end{abstract}

Keywords: Cardiac rehabilitation; malta mater dei hospital; nurse.

Cite this article as: Sevinç S. Nurse-Led Cardiac Rehabilitation Clinic: Experience in Malta Mater Dei Hospital. Turk J Cardiovasc Nurs 2020;11(26):155-158.

$\mathrm{K}$ alp ve damar hastalıkları Ülkemizde ve dünyada mortaite ve morbidite açısından en önde gelmektedir. Türkiye İstatistik Kurumu (TÜiK) verilerine göre ölümlerin çoğu dolaşım sistemi hastalıkları nedeniyle meydana gelmektedir ve bu hastalıklar ölüm nedenleri arasında birinci sıradadır. $^{[1]}$ Kalp ve damar hastalıklarına bağlı ölümlerin 2030 yı- lında 22.2 milyon olacağı tahmin edilmektedir. ${ }^{[2]}$ TÜiK ölüm verileri toplam ölümlerin içinde kalp hastalıklarının payının gittikçe artma eğiliminde olduğunu göstermektedir. ${ }^{[1]}$ Türkiye'de Erişkinlerde Kalp Hastalığı ve Risk Faktörleri Sıklığı (TEKHARF) çalışmasının son takipleri, Türk erişkinlerinde hem kalp hastalıkları mortalitesi hem de yeni koroner olay

İletişim (Correspondence): Sibel Sevinç. Hatay Mustafa Kemal Üniversitesi, Sağlık Bilimleri Fakültesi, Hemşirelik Bölümü, İç Hastalıkları Hemşireliği Anabilim Dalı, Hatay

Telefon (Phone): +90 5425959283 E-Posta (E-mail): sibelsevis@gmail.com

Başvuru Tarihi (Submitted Date): 01.09.2020 Kabul Tarihi (Accepted Date): 14.12.2020

CCopyright 2020 by Turkish Society of Cardiology - Available online at www.anatoljcardiol.com

OPEN ACCESS This work is licensed under a Creative Commons Attribution-NonCommercial 4.0 International License. 
prevalansının gereğinden ve çevre ülkelerindekinden her iki cinsiyette yüksek olduğuna dair önceki kanıtları desteklemiş, ülkemizde koroner hastalıktan koruyucu önlemleri çok daha etkinleştirme gereğini vurgulamıştır. ${ }^{[3]}$ Yine Türkiye Kalp ve Damar Hastalıkları Önleme ve Kontrol Programı 2015-2020 hedeflerinde de, Kalp ve damar hastalıkları ile ilgilenen uzmanlık dalları (kardiyoloji, kalp ve damar cerrahisi vb.) ve diğer sağlık personelinin kardiyak ve serebrovasküler rehabilitasyon konusunda bilinçlendirilmesi, kardiyak ve serebrovasküler hastalıklarda evde sağlık/palyatif bakım hizmetleri kapsamında rehabilitasyon hizmetlerinin oluşturulması bulunmaktadır. ${ }^{[2]}$

Yüksek gelir düzeyine sahip ülkelerde son 20 yılda kalp ve damar hastalıklarından kaynaklanan mortalite azalmaktadır. Tüm nüfusu kapsayan primer önleme ve bireysel müdahalelerin birlikte etkili olduğu görülmektedir. İngiltere'de 1981'den 2000 yılına kadar koroner kalp hastalığına bağlı mortalitede belirgin bir düşüş olmuştur. Bu düşüşün yaklaşık yüzde 42'si tedaviyle ilişkilidir (yüzde 11'i ikincil önleme, yüzde 13 kalp yetmezliği tedavisi, yüzde 8 akut miyokard infarktüsünde başlangıç tedavisi, yüzde 3 hipertansiyon tedavisi). Geri kalan yaklaşık yüzde $58^{\prime}$ lik düşüş tüm nüfusu kapsayan risk faktörlerini azaltmaya yönelik çalışmalara bağlıdır. ${ }^{[2]} \mathrm{Ki}$ bu sonuçlarda risk faktörlerini azaltmaya ilişkin yapılacak girişimlerin ne kadar önemli olduğunu bir kez daha kanıtlamaktadır.

Avrupa Klinik Uygulamada Kardiyovasküler Hastalıklardan Korunma Kılavuzu (2012)'nda belirtildiğine göre; yapılan randomize çalışmalarda, ikincil korunma alanında hemşire olgu yönetimi araştırmaları, egzersiz toleransında, kan şekeri düzenlenmesinde, risk fakötrlerinde, ilaç kullanımına uyumda iyileşme olduğunu göstermiştir. Tüm bunların yanında, hastanın sağlık algısında düzelme, mortalite ve morbiditede düşüş, hatta koroner aterosklerozda gerileme rapor edilmiştir. ${ }^{[4]}$

Hastane ve birinci basamak sağlık uygulamalarında yer alan bir hemşire eşgüdümlü çok disiplinli korunma programı, kardiyovasküler hastalığı (KVH) olan ve $\mathrm{KVH}$ için yüksek risk taşıyan hastaların alındığı sekiz ülkede yürütülen EUROACTION çalışmasında değerlendirilmiştir. Aile merkezli yaklaşımla, girişim grubunda yaşam tarzında beslenme ve fiziksel aktivite gibi konularda iyileşmeler olduğu, eşlerde ve hastalarda kan basıncı gibi risk faktörlerinin daha etkili yönetilebildiği gösterilmiştir. Programın önemli bir özelliği de, bu tip bir programın Avrupa'da sekiz farklı sağlık sisteminde, özgül merkezler dışında, hastaneler ve genel uygulama merkezlerinde de uygulanabilirliğinin gösterilmesidir. ${ }^{[5]}$
Koruyucu Kardiyovasküler Hemşireler Birliği, Kardiyovasküler Hemşirelik ve İlişkili Meslekler Kurulu (CCNAP: Council on Cardiovascular Nursing and Allied Professions) ve AHA Kardiyovasküler Hemşirelik Kurulu yeni bir uzlaşı belgesi hazırlayarak, hemşirelere KVH'dan korunmada daha aktif faaliyet göstermeleri konusunda çağrı yapmıştır (kılavuz, 2012). Kanıtlar da, hemşire olgu yönetimi ve hemşire-eşgüdümlü multidispliner korunma programlarının kardiyovasküler riski azaltmada olağan bakımdan daha etkili olduğunu ve çeşitli sağlık kuruluşlarının koşullarına uyarlanabileceğini göstermektedir. Hemşireler sağlık sisteminde iş gücünün büyük bir bölümünü oluşturmaktadır ve pek çok ülkede eğitim programlarının bir kısmı, hasta eğitimi ve danışmanlık, iletişim ve davranış değişikliklerini sağlama üzerine odaklanmıştır ki, bunlar da korunma programı için istenilen becerilerdir. Aynı zamanda, hemşireler toplum tarafından güvenilir bilgi ve yardım kaynakları olarak görülmekte ve hemşirelik görevi tipik olarak bakımın koordinasyonunu ve çok sayıda sağlık görevlisi ile işbirliğini içermektedir. Avrupa'da bu tip programların zorluklarından biri sağlık sistemlerindeki farklıııkların yanı sıra, ülkeler arasında hemşirelik eğitimi ve uygulamalarında da değişkenlik olması ve hemşirelerin geleneksel görevlerinin ötesinde, daha az bağımsız hareket etmelerinin kabulüdür. Ancak, etkin korunma programlarının gerekliliği yadsınamaz ve kanıtlar hemşirelerin çeşitli sağlık düzenlerde bu tip şemaları başarıyla yürütebildiklerini veya koordine edebildiklerini göstermektedir. ${ }^{[4]}$

Bu makalenin amacl; yazar tarafından 2017 yılı Haziran ayında belirtilen hastanenin hemşire yönetimindeki kardiyak rehabilitasyon kliniğine yapılan ziyaret sonucundaki gözlemlerinin ve hemşire yönetimindeki bir program örneğinin paylaşılmasıdır.

\section{Hemşire Yönetimindeki Kardiyak Rehabilitasyon Programı}

Program aktif görev yapan iki hemşire, iki fizyoterapist tarafından yürütülmekte, programın sorumlu hemşiresi ve bir fizyoterapist, Londra'dan (Imperial College) 16 haftalık kardiyak rehabilitasyon kurs programı sertifikalı ve koruyucu kardiyoloji yüksek lisans eğitimine sahip. Ekipte aktif olarak rol almasa da kardiyolog, diyetisyen, psikolog, beslenme uzmanı da yer almakta. Programdaki tüm uygulamalar Avrupa Kardiyoloji Derneği kılavuzlarına göre yapılıyor. Program hastanın bireysel özellikleri ve mevcut risk faktörlerine göre 6 ve 16 hafta arasında sürüyor. Programda By-Pass sonrası hastalar, Koroner arter hastaları, perkütan girişim sonrası hastalar, kalp yetmezliği (KY) ve hipertansiyon (HT) hastaları mevcut. Program tamamlandıktan 
sonra hastaların takibi klinikte devam ediyor. Hastaların hastane kayıtlarından iletişim bilgilerine ulaşılıyor ve taburculuklarının bir ay sonrasında ev adreslerine programa davet mektubu gönderiliyor. Mektupla ulaşılamayan hastalar telefonla aranarak programa davet ediliyor. Her Salı günü programa davet edilen hastaların değerlendirilmesi, her Cuma günü de programa yeni kabul edilen hastalar için ilk bilgilendirme toplantısı yapılıyor. Haftada üç ayrı hasta grubunun programı devam ediyor. Her hasta grubunda 10-15 kayıtlı hasta bulunuyor. Pazartesi ve Perşembe günleri aynı iki grup, Çarşamba- Cuma günleri diğer kayıtlı bir grupla program yürütülüyor. Diyabet eğitim programının içinde yer almıyor, diyabetli bireyler diyabetle ilgili başka bir programa daha katılıyorlar. Eğitimler konularına göre ekipteki profesyoneller tarafından yapılıyor. Başlangıçtan 16 hafta sonra ikinci değerlendirme yapılıyor. Bir yıl sonra üçüncü değerlendirmeleri yapılıyor. Hastalar faz 3 rehabilitasyonla başlayıp, direnç egzersizleri yaparken, faz 4 rehabilitasyonla hastanede ya da evde programlarına devam ediyorlar. Faz 3 egzersizleri ısınma egzersizleri ile başlayıp 10 farklı direnç egzersizin ardışık olarak birer dakika yapılmasıyla devam ediyor ve egzersiz sonunda soğuma hareketleri fizyoterapist tarafından yaptırılıyor. Faz 4 aşamadaki bireyler ve obez bireyler için hastane egzersiz salonunda yürüyüş bandı ya da bisiklet, ev programı için her gün 45 dakika yürüyüş öneriliyor. Hastaların sigara içme düzeyleri kanlarındaki CO gazını ölçen basit bir cihazla yapılıyor. Kan tetkikleri hekim istemi söz konusu olmadan, kardiyak rehabilitasyon kliniği standartlarına göre yapılıyor. Program sonunda hastaların başlangıç, 16 hafta sonraki, 1 yıl sonraki değerleri bilgisayarda sisteme kayıt ediliyor ve hastane yönetimi ile ülkenin sağlık bakanlığıyla paylaşılıyor. Programın sonuçları ülkenin ulusal kardiyoloji kongresinde her yıl bildiri olarak da paylaşılıyor. Sağlık bakanlığı ve hastane yönetimi hastalardaki olumlu değişimi, programın hastalar için yararını fark ettikten sonra programa desteğini daha fazla arttırmış durumda.

\section{Altı Haftalık Eğitim Konuları}

\section{Hafta}

Koroner arter hastalığının basit fizyopatolojisi. Semptomlar ve göğüs ağrısı

\section{Hafta}

Risk faktörleri. Hipertansiyon ve yönetimi

\section{Hafta}

Kolesterol. Kalp hastalığının etkisi

\section{Hafta}

Egzersizin önemi. Stres yönetimi

\section{Hafta}

Diyet. Tüm konuların anlaşılması

\section{Hafta}

Engellerin yönetimi. Tıbbi tedavi.

Programın bir haftalık süreci aşağıdaki şekilde devam ediyor.

\section{Pazartesi}

Programa kayıtlı hastalardan I. Grup için 8.30 da hastanenin egzersiz salonunda fizyoterapist eşliğinde egzersiz başlıyor ve $9.15^{\prime}$ e kadar devam ediyor. Saat $9.30^{\prime}$ da bilgilendirme toplantısı yapılıyor. Aile üyeleri de bu toplantıya katılabiliyor. Saat 9.30-10.15 arası yapılan bilgilendirme toplantısına I. ve II. Grup katılıyor. Saat 10.30-11.15 arası II. Hasta grubunun egzersizi yapılıyor. Egzersiz sonrası soğuma hareketleri yapılıyor ve hastaların kan basınçları, kalp hızları ve $\mathrm{SpO}_{2}$ değerleri ölçülüp kayıt ediliyor.

\section{Salı}

Programa davet edilen hastaların hemşire, diyetisyen ve fizyoterapist tarafından değerlendirilmesi, hastaların risk faktörlerinin kan değerlerinin belirlenmesi için tetkiklerinin yapılması, boy-kilo bel çevresi değerlerinin belirlenmesi, CO cihazıyla sigara içme durumlarının belirlenmesi, programa kabulü yapılıyor.

\section{Çarşamba}

Saat 11.00-11.45 arası faz 3 aşamasındaki bireyler için bilgilendirme toplantısı yapılıyor, 12.00-13:00 arası egzersiz salonunda egzersize devam ediliyor. Faz 4 bireylerle 11.0013.00 arası egzersiz salonunda egzersizler fizyoterapist tarafından devam ettiriliyor.

Sabah 8.00-11.00 arasında başlangıç, izlem ve program sonrası hastalar için fizyoterapist tarafından 6 dakikalık koridor yürüme testi yapılıyor. Bu testle hastaların başlangıç, izlem ve son fonksiyonel kapasiteleri belirleniyor. Ayrıca fizyoterapist hastaların MET değerlerini belirleyip başlangıç aşamasında olanlar için kimlik kartları düzenleniyor, hastalar egzersiz sırasında bu kimlik kartlarını yakalarına takıyorlar, böylece ekipteki herkes hastanın yürüme hızını ve MET değerini kimliğinden okuyabiliyor.

\section{Perşembe}

Pazartesi programa devam eden bireyler için ikinci toplantı günü. Aynı şekilde 1. grup hasta egzersize başlayıp bilgilendirme toplantısına katılıyor, 2. Grup hasta bilgilendirme toplantısına katılıp egzersize devam ediyor.

\section{Cuma}

Çarşamba günü gelen hasta grubunun ikinci günü, sabah ise Çarşamba günkü gibi takip ve fizyoterapist tarafından 6 daki- 
kalık koridor yürüme testi yapılıyor. Programa yeni başlayan hastalar için ilk bilgilendirme toplantısı da bugün yapılıyor.

Hastanede aynı zamanda hemşire yönetiminde olan diyabet kliniği, enfeksiyon kontrolü, taburculuk eğitimi ekibi, kalp yetmezliği polikliniği hizmet veriyor.

\section{Sonuç}

Akut koroner olay sonrası kardiyak rehabilitasyon düşük maliyetli bir girişim olarak kabul edilmektedir; ömrü uzatır, tekrarlayan hastane yatışlarını ve sağlık harcamalarını azaltarak hastalığın seyrini iyileştirir. Kardiyak olay sonrası kardiyak rehabilitasyon ESC, AHA ve Amerikan Kardiyoloji Topluluğunun Sınıf I önerisidir. Kardiyak rehabilitasyonunun hedefleri ve çekirdek bileşenleri standardize edilmiş ve bir görüş bildirisi ile belgelenmişse de, kardiyak rehabilitasyon birimlerinin yapısı ve tipi ülkelere göre farklııklar gösterir. Sağlık sisteminin gelenekleri ve maliyet değerlendirmeleri önemli rol oynar. Hastanın alıştığı ortamından uzaklaştırıldığı, gerekli ilaçlara alışana kadar 2-3 hafta ideal çevrede yaşadığı ve sağlıklı bir yaşam tarzı eğitimi aldığı yatılı kardiyak rehabilitasyon merkezleri bazı Avrupa ülkelerinde seçeneklerden biridir ve genellikle bunu ev ortamında ayaktan eğitim dönemi izler. Diğer Avrupa ülkeleri ayaktan rehabilitasyon ünitelerini tercih etmektedir. Bu tip ünitelerde hasta birkaç ay süreyle haftada bir ya da iki kez bir rehabilitasyon oturumuna katılır ve işe döndükten sonrası dahil olmak üzere, kendi alıştığı çevrede yaşam tarzı önerilerini uygu- lamaya çalışır. ${ }^{[4]} \mathrm{Bu}$ makale hemşire yönetimdeki bir kardiyak rehabilitasyon programını tanıtmak için yazılmıştır. Bu örneğin kardiyoloji hemşireliği literatürü için bir kaynak oluşturacağı, klinisyen hemşireler için de yol göstereceği olacağı düşünülmektedir.

Hakem Değerlendirmesi: Dış bağımsız.

Çıkar Çatışması: Yazarlar arasında herhangi bir çıkar çatışması bulunmamaktadır.

\section{Kaynaklar}

1. T.C. Sağlık Bakanlığı. Sağlık İstatistikleri Yıllığı 2018, Yayın No, 1106. Available at : https://dosyasb.saglik.gov.tr/Eklenti/36134,siy2018trpdf.pdf?0. Accessed July 24, 2019.

2. T.C. Sağlık Bakanlığı. Türkiye Halk Sağlığı Kurumu Türkiye Kalp ve Damar Hastalıkları Önleme ve Kontrol Programı 2015-2020. Available at: https://tkd.org.tr/TKDData/Uploads/files/Turkiye-kalp-ve-damar-hastaliklari-onleme-ve-kontrol-programi. pdf. Accessed July 24, 2019.

3. Onat A. TEKHARF 2017 Tıp Dünyasının Kronik Hastalıklara Yaklaşımına Öncülük. İstanbul: Logos Yayıncılık Tic. A.Ş,; 2017.

4. Avrupa Kardiyoloji Derneği ile Klinik Uygulamada Kardiyovasküler Hastalıklardan Korunma Üzerinde Çalışan Diğer Derneklerin Beşinci Birleşik Görev Grubu. Avrupa Klinik Uygulamada Kardiyovasküler Hastalıklardan Korunma Kılavuzu (Versiyon 2012). Turk Kardiyol Dern Ars 2012;40(3):1-76.

5. The EUROACTION Trial. Available at: https://www.escardio. org/The-ESC/Press-Office/Press-releases/The-EUROACTION-Trial. Accessed July 24, 2019. 